\title{
Evaluation of Role of Anterior Debridement and Decompression of Spinal Cord and Instrumentation in Treatment of Tubercular Spondylitis
}

\author{
Saurabh Singh, Vinay Kumaraswamy, Nitin Sharma, Shyam Kumar Saraf, Ghanshyam Narayan Khare
}

Department of Orthopedics, Institute of Medical Science, Banaras Hindu University, Varanasi, India

\begin{abstract}
Study Design: Prospective study with simple randomization.
Purpose: To evaluate the results of anterior spinal instrumentation, debridement and decompression of cord and compare it with results of a similar procedure done without the use of anterior instrumentation.

Overview of Literature: Use of anterior spinal instrumentation in treatment of tubercular spondylitis is still an infrequently followed modality of treatment and data regarding its usefulness are still emerging.

Methods: Thirty-two patients of tubercular paraplegia with involvement of dorsal and dorso-lumbar vertebrae were operated with anterior spinal cord decompression, autofibular strut grafting with anterior instrumentation in 18 patients and no implant in 14 patients. Results were compared on the basis of improvement in Frankel grade, correction of local kyphosis, decrease in canal compromise and further progression of kyphosis.

Results: The mean local kyphosis correction in the immediate postoperative period was $24.1^{\circ}$ in the instrumented group and was $6.1^{\circ}$ in the non instrumented group. The mean late loss of correction of local kyphosis at 3 years follow-up was $1.7^{\circ}$ in the instrumented and $6.7^{\circ}$ in the non instrumented group. The mean improvement in canal compression was $39.5 \%$ in the instrumented group and $34.8 \%$ in the non instrumented group.

Conclusions: In treatment of tubercular spondylitis by anterior debridement and decompression of the spinal cord and autofibular strut grafting, the use of instrumentation has no relation with the improvement in neurological status, however the correction of local kyphosis and prevention of further progression of local kyphosis was better with the use anterior spinal instrumentation.
\end{abstract}

Key Words: Tuberculosis, Instrumentation, Kyphosis, Paraplegia

\section{Introduction}

The management of tuberculous spondylitis is not uniform throughout the world [1]. Chemotherapy appears to be the mainstay in the treatment of tuberculous spondylitis. Kyphosis in spinal tuberculosis continues to progress with conservative treatment and about $3 \%$ to $5 \%$ of cases will have severe progression [2,3]. Indications for surgery in spinal tuberculosis are reported to include the presence of a large paraspinal abscess, the presence of severe bone destruction and kyphotic deformity, neurological deficit with spinal cord compression and lack of response to medical treatment [4]. Anterior debridement, strut grafting and instrumentation have an increasing popularity in the treatment of tuberculous spondylitis. Anterior fixation can be done either by the plate or rod system [5].

Received Nov 3, 2011; Revised Feb 5, 2012; Accepted Feb 26, 2012

Corresponding author: Nitin Sharma, MS

Department of Orthopedics, Institute of Medical Science, Banaras Hindu University,

P.O. Box 221005, Varanasi, Uttar Pradesh, India

Tel: +91-8601116000, Fax: +91-54215023150, E-mail: krishnaaa10@gmail.com 
Anterior instrumentation appears to be more advantageous than posterior instrumentation, as both instrumentation and grafting are done as a single stage procedure through the same approach minimizing blood loss, operative time and graft slipping out due to turning of the patient for posterior instrumentation. It also prevents fusing an unnecessarily large number of spinal levels. The problems with this approach are lack of adequate space to insert the anterior implants and the possible problem of prominent hardware impaling the great vessels particularly in the thoracic spine. Further retrieval of dislodged anterior hardware is more risky and fixation in cancellous vertebral bodies gives less pullout strength compared to fixation in the dense pedicles [6,7]. We in this study intend to evaluate the results of anterior debridement, autofibular strut grafting with anterior instumentation and also evaluate the outcome of similar procedure done without the use of instrumentation.

\section{Material and Methods}

Thirty-two patients were operated with anterior debridement, spinal cord decompression and anterior fusion and had a minimum follow-up of 3 years. Inclusion criteria were patients of tuberculous spondylitis, type III as per Gulhane Askeri Tip Akademisi (GATA) classification [8], between 20 and 70 years. Patients younger than 20 years and older than 70 years were excluded from the study. Patients of dorsal and dorso-lumbar tubercular spondylitis with paraplegia were included. Patients of tuberculosis of cervical, lower lumbar, lumbosacral spine and multi level tuberculous spondylitis were excluded from the study. Indications for surgery were neulogical involvement in the form of paraplegia. The preoperative diagnosis was made on the basis of clinical examination, plain radiograph and magnetic resonance imaging (MRI) supported by serological investigation (erythrocyte sedimentation rate, ESR) and in each case the histopathologic diagnosis of tuberculosis was confirmed after surgery. Patients with neural deficits were graded according to the Frankel's scale [9]. Raised ESR was a common feature. Radiological evaluation and MRI evaluation was done in all patients prior to surgery and level of involvement, angle of local kyphosis and percentage of canal compromise was calculated. Local kyphosis was measured as the angle between the upper and lower end plates of the collapsed vertebrae preoperatively, postoperatively and at the last follow-up visit (Fig. 1). Vertebral collapse, destruction, cold abscess were assessed in MRI, and canal compromise (stenosis) were calculated from axial cuts of computed tomography (CT) scans. Canal compromise was calculated by the formula-[(A+C) / 2] - B / $(\mathrm{A}+\mathrm{C})\} \times 100$ [1]-'A' is unaffected spinal canal above, ' $C$ ' is the most affected level of the spinal canal, and ' $\mathrm{B}$ ' is unaffected spinal canal below (Fig. 2) [1].

Simple randomization was used to divide patients into groups and it was a prospective study design.

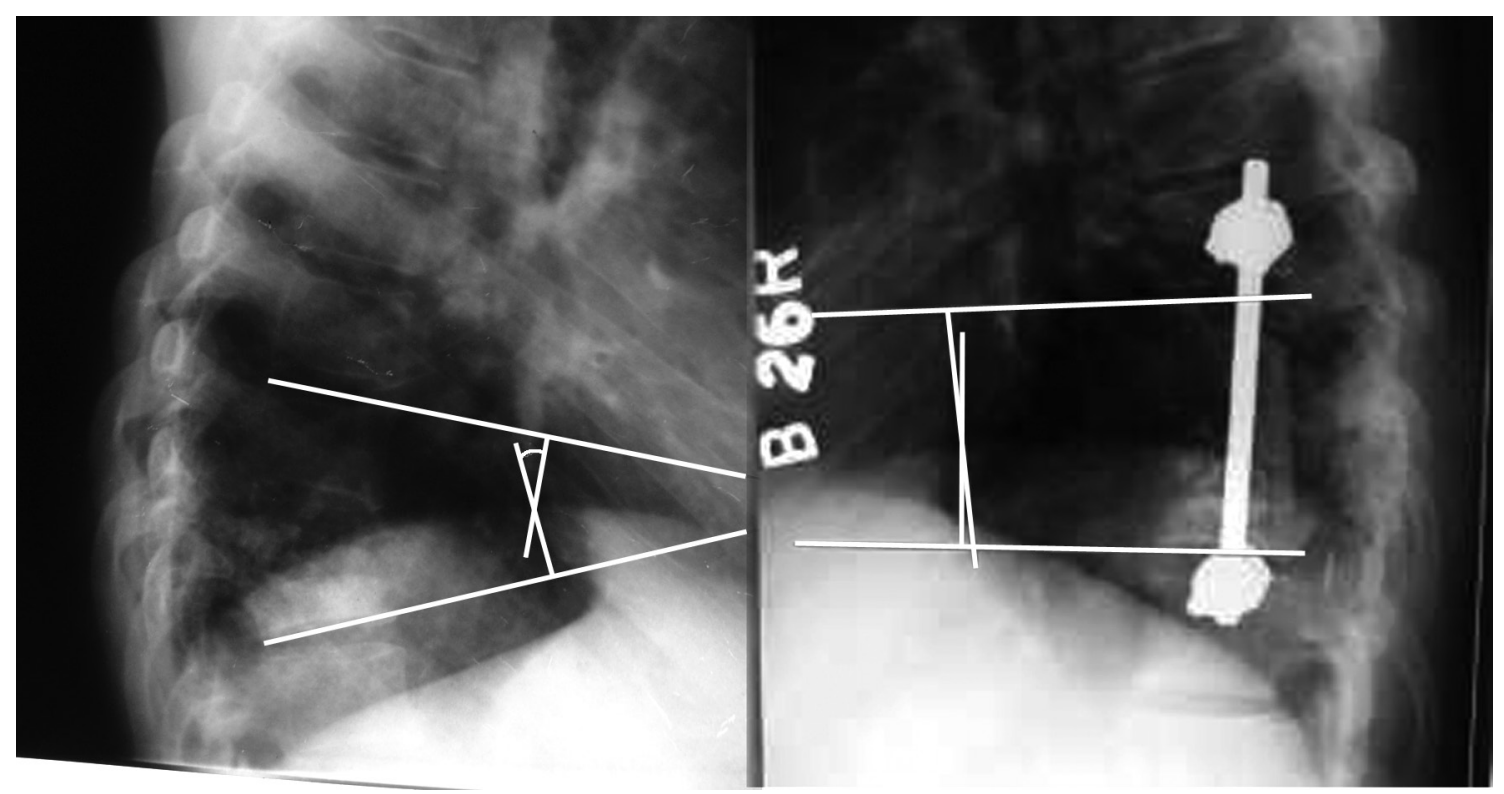

Fig. 1. Showing method of measurement of local kyphosis. Local kyphosis was measured as the angle between the upper and lower end plates of the collapsed vertebrae preoperatively, postoperatively and at the last followup visit. 


\section{Operative procedure}

With the patient in left lateral position, access was gained to the involved vertebrae by means of thoracotomy. Single lung ventilation was carried out after thoracotomy with the left lung deflated to improve exposure and to avoid inadvertent injury to the lungs. The abscess was drained if present and neural decompression was done with complete corpectomy of the destroyed vertebra leaving only a shell of bone of the opposite cortex. Patency of the spinal canal is confirmed by inserting an infant feeding tube proximally and distally. Before inserting the strut graft slots are made in the proximal and the distal healthy vertebral body. The kyphus is corrected manually by applying anterior pressure at its apex [10]. When the pressure on the back of the spine is released, the graft is locked in position. Remaining gap is filled with rib that was resected during exposure and supplemented by auto iliac bone graft. Anterior instrumentation, when done was in the form of titanium interbody screws in the proximal and distal normal vertebral bodies connected together with titanium rods (Fig. 3). The lungs are inflated to check that no inadvertent pleural tear has been made before wound closure over a chest drain.

Sitting with brace support was allowed from 3rd postoperative day in instrumented patients and at 3 weeks onwards in non-instrumented patients. In both the groups, brace

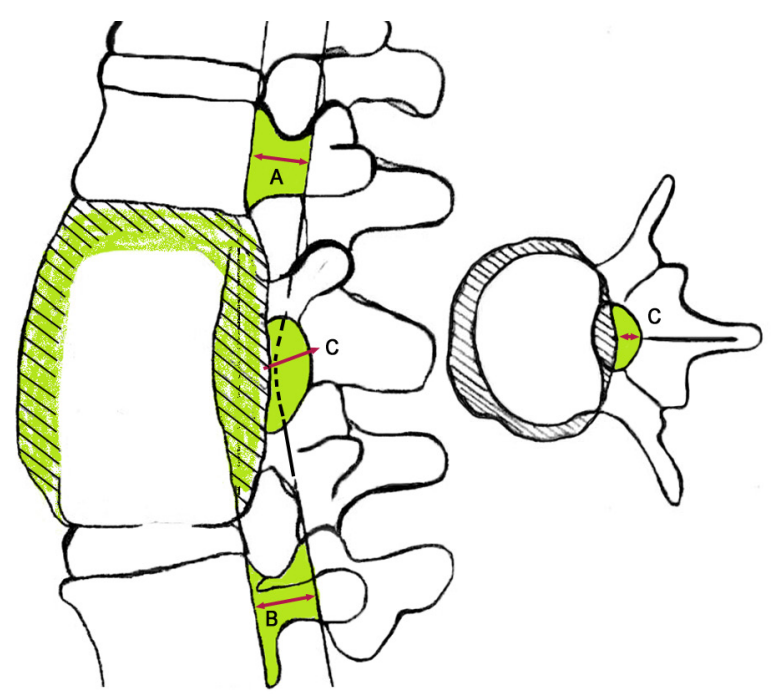

Fig. 2. Schematic drawings show the percentage of spinal canal compromise. (A) Unaffected spinal canal above. (B) Unaffected spinal canal below. (C) The most affected level of the spinal canal. Formula for calculating canal compromise- $\{[(\mathrm{A}+\mathrm{C}) / 2]-\mathrm{B} /(\mathrm{A}+\mathrm{C})\} \times 100[1])$. was used for support in the initial 6 months and full weight bearing when radiological signs of fusion were evident was followed in both groups. Follow-up was done at 1, 3, 6, $9,12,18$ months following surgery and at every 6 months thereafter. Radiological and lab investigation, including the erythrocyte sedimentation rate were done at each followup visit. Frankel grade was evaluated clinically. Immediate postoperative ocal kyphosis correction was calculated from plain radiographs taken at postoperative day 3. Late loss of kyphosis was measured by the plain radiograph taken 3 years postoperatively. From the time of initial diagnosis and continuing postoperatively, anti tubercular drugs were given as per the national government's protocol.

The patients were classified according to the GATA classification [8]. All patients were of GATA type III and were randomly assigned to the 2 groups. Both groups had in common anterior debridement and decompression of spinal cord and autofibular strut grafting. One group had additional anterior stabilization with screws and rods (hereafter referred to as group 1) (Fig. 3) and the other group was not instrumented (hereafter referred to as group 2) (Fig. 4).

The statistical methods used were independent sample t-test for improvement in local kyphosis, loss of correction at 3 years and for improvement in canal stenosis and chisquare test for improvement in neurological status.

\section{Results}

There were 17 males and 15 females included in the study (Tables 1 and 2). The average follow-up was 41.6 months (range, 36 to 52 months). The patients had an average age of 41.4 years with the age ranging from 23 years to 68 years. The two groups (group 1 and 2) were matched and found similar according to age (mean 40.3 vs. 43 years), average number of involved levels (1.16 vs. 1.28), location of involved levels, severity of deformity $\left(33.6^{\circ}\right.$ vs. $\left.31.4^{\circ}\right)$ and type of autografts used. The most common involved level was thoracic D7-D8 spine in both the groups. Statistical test of significance used was the student t-test.

In our study the percentage correction in local kyphosis in group 1 was $72.02 \%$ (mean, $24.2^{\circ}$ ) (Table 3 ) and the late loss of correction at last follow-up of 3 years has been $1.7^{\circ}$ which correlates with other studies published in the literature. The percentage local kyphosis correction in group 2 was $19.42 \%$ (mean, $6.1^{\circ}$ ) and the late loss of correction at last follow-up of 3 years has been $6.7^{\circ}$. Improvement in canal compression was $39.98 \%$ in group 1 and $34.8 \%$ in 
group 2. The difference in improvement in canal stenosis between the two groups was not significant ( $p=0.367)$. However improvement in local kyphosis was significantly better in the instrumented group $(p<0.001)$ and the late loss of correction in the instrumented group was also signifi- cantly lesser $(p=0.01)$. There were no episodes of wound infection, development of new discharging sinuses and recurrence of the disease at the same or any other level in the spine in either of the 2 groups.

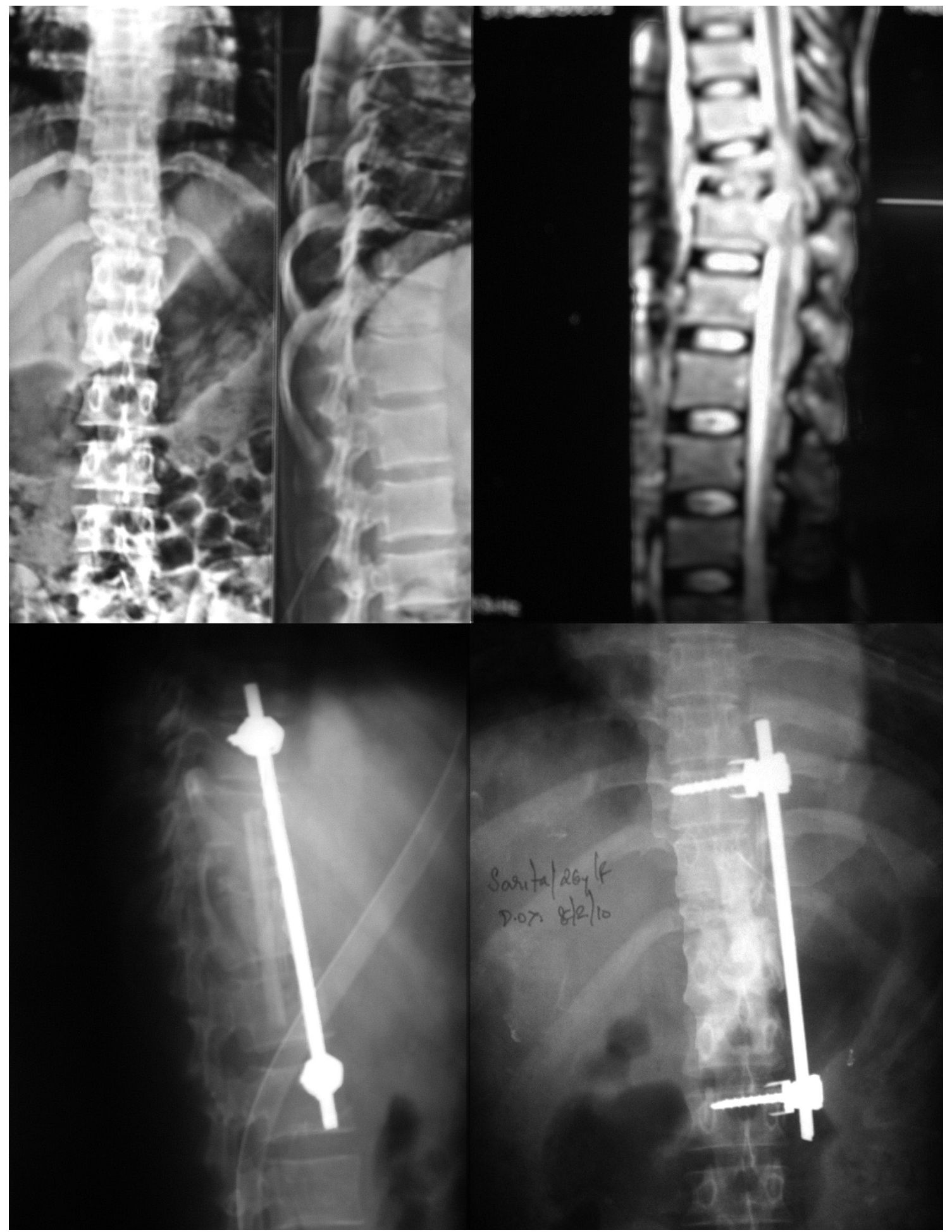

Fig. 3. Preoperative radiograph, preoperative magnetic resonance imaging picture and postoperative radiograph of a patient with tuberculosis of D12 vertebra for which anterior debridement, fibular strut grafting and instrumentation has been done. 


\section{Discussion}

The most frequent site for extra pulmonary involvement of tuberculosis infection in the body is the vertebral column [11]. Prior to the era of antibiotics and improvements in general health, multisegmental involvement was thought to be the norm, usually diagnosed at the autopsies, but today involvement of more than one noncontiguous region of the spine is a very rare entity [11]. Earlier with only antitubercular drugs for treatment of tubercular spondylitis, the objective was to achieve healed status, but there were the sequelae of kyphosis. These days the goal of treatment is to cure the disease, with no sequelae of neural complications and an almost near normal functional spine.

The role of using spinal instrumentation in caries spine has two issues to be addressed. The first issue considered is about putting in a foreign body in an infected vertebral zone. The first clinical and biological study about the same was published about 18 years back and was shown to be experimentally safe with the added newer generation of antitubercular medicines [12]. Subsequently it was questioned whether it is better to put in

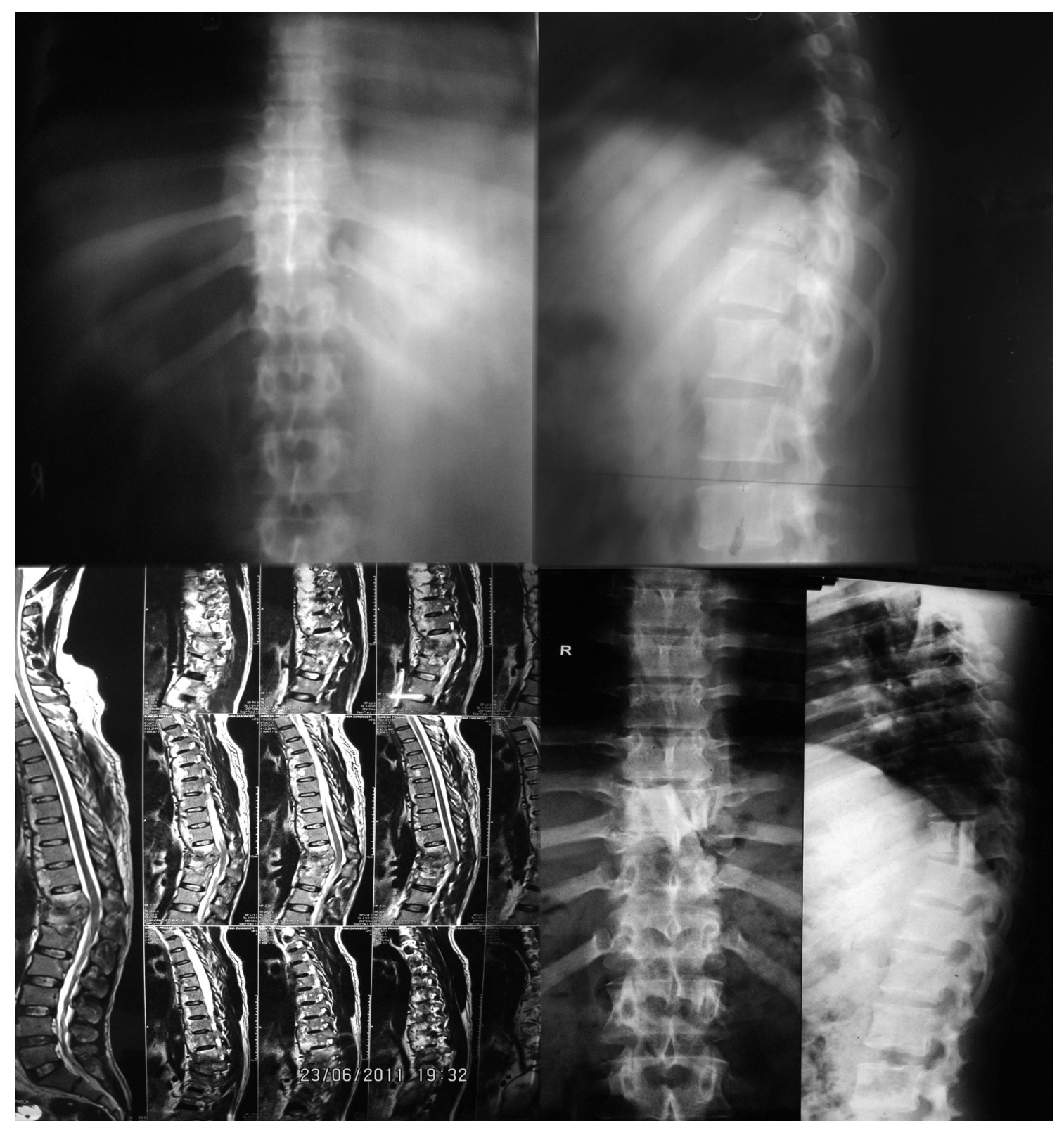

Fig. 4. Preoperative radiograph, preoperative magnetic resonance imaging picture and postoperative radiograph of a patient with tuberculosis of lower dorsal vertebra for which anterior debridement, fibular strut grafting has been done without instrumentation. 
Table 1. Table showing all cases in the study, their neurology before and after surgery and pre- and postoperative canal stenosis

\begin{tabular}{|c|c|c|c|c|c|c|c|c|c|}
\hline $\begin{array}{l}\text { Patient } \\
\text { No. }\end{array}$ & $\begin{array}{c}\text { No. of } \\
\text { vertebrae } \\
\text { involved }\end{array}$ & Vertebral level & $\begin{array}{l}\text { Age } \\
(\mathrm{yr})\end{array}$ & Sex & $\begin{array}{l}\text { No. of } \\
\text { segments } \\
\text { fixed }\end{array}$ & $\begin{array}{l}\text { Neurology } \\
\text { before surgery } \\
\text { (Frankel } \\
\text { grade) }\end{array}$ & $\begin{array}{c}\text { Neurology at } \\
3 \text { years } \\
\text { follow-up } \\
\text { (Frankel grade) }\end{array}$ & $\begin{array}{l}\text { Canal stenosis } \\
\text { preoperative }\end{array}$ & $\begin{array}{l}\text { Canal stenosis } \\
\text { postoperative }\end{array}$ \\
\hline
\end{tabular}

Group 1 (instrumented patients)

$\begin{array}{cccccc}1 & 2 & \text { D5-D6 } & 48 & \text { F } & 3 \\ 2 & 2 & \text { D9-D10 } & 41 & \text { M } & 3 \\ 3 & 3 & \text { D6, D7, D8 } & 37 & \text { F } & 3 \\ 4 & 2 & \text { D4-D5 } & 26 & \text { F } & 3 \\ 5 & 3 & \text { D8, D9, D10 } & 62 & \text { F } & 4 \\ 6 & 3 & \text { D10, D11, D12 } & 52 & \text { M } & 4 \\ 7 & 2 & \text { D7-D8 } & 37 & \text { M } & 3 \\ 8 & 3 & \text { D8, D9, D10 } & 26 & \text { M } & 3 \\ 9 & 2 & \text { D7-D8 } & 32 & \text { M } & 3 \\ 10 & 2 & \text { D7-D8 } & 68 & \text { F } & 3 \\ 11 & 2 & \text { D10-D11 } & 46 & \text { M } & 3 \\ 12 & 2 & \text { D12-L1 } & 35 & \text { F } & 3 \\ 13 & 2 & \text { D9-D10 } & 31 & \text { M } & 3 \\ 14 & 2 & \text { D5-D6 } & 52 & \text { M } & 3 \\ 15 & 2 & \text { D9-D10 } & 24 & \text { F } & 3 \\ 16 & 2 & \text { D5-D6 } & 35 & \text { F } & 3 \\ 17 & 2 & \text { D7-D8 } & 44 & \text { M } & 3 \\ 18 & 2 & \text { D10-D11 } & 29 & \text { F } & 3\end{array}$

$\begin{array}{lccc}\text { A } & \text { E } & 43 & 6 \\ \text { A } & \text { E } & 32 & 7 \\ \text { A } & \text { E } & 65 & 10 \\ \text { A } & \text { E } & 47 & 14 \\ \text { A } & \text { E } & 57 & 13 \\ \text { A } & \text { E } & 42 & 16 \\ \text { A } & \text { E } & 58 & 5 \\ \text { A } & \text { E } & 61 & 9 \\ \text { B } & \text { E } & 39 & 7\end{array}$

A

A $\quad$ E

A

A

A

A

A

A

A

A

B

A

A

A

A

A

A

A

A

B

A

A

A
Died on 2nd postoperative day $^{\text {a) }}$

7

5

15

18

15

3

8

12

Group 2 (non instrumented patients)

$\begin{array}{llcccc}11 & 2 & \text { D9-D10 } & 46 & \text { F } & 1 \\ 12 & 2 & \text { D7-D8 } & 52 & \text { M } & 1 \\ 13 & 2 & \text { D9-D10 } & 22 & \text { M } & 1 \\ 14 & 2 & \text { D6-D7 } & 44 & \text { F } & 1\end{array}$

$\begin{array}{cccc} & \text { E } & 52 & 16 \\ \text { E } & 76 & 12 \\ \text { E } & 57 & 8 \\ \text { E } & 73 & 24 \\ \text { E } & 67 & 18 \\ \text { E } & 36 & 13 \\ \text { E } & 35 & 20 \\ \text { E } & 25 & 8 \\ \text { D } & 37 & 9 \\ \text { E } & 48 & 12 \\ \text { E } & 53 & 18 \\ \text { E } & 32 & 9 \\ \text { E } & 43 & 10 \\ \text { E } & 48 & 18\end{array}$

a) This was a 68-year-old female patient in the instrumented group (group 1). She had other associated comorbidities along with tuberculosis. The patient was a case of known coronary artery disease with poor cardiac and pulmonary reserve along with chronic hypertension. The patient died of acute myocardial infarction on the 2 nd postoperative day. 
Table 2. Table showing all cases in the study, their angle of local kyphosis pre- and postsurgery and at 3 years follow-up

\begin{tabular}{|c|c|c|c|c|c|}
\hline $\begin{array}{l}\text { Serial } \\
\text { index } \\
\text { No. }\end{array}$ & $\begin{array}{c}\text { Angle of kyphosis } \\
\text { before the operation } \\
\left(^{\circ}\right)\end{array}$ & $\begin{array}{l}\text { Angle of local kyphosis } \\
\text { (immediate postoperative, }\end{array}$ & $\begin{array}{c}\text { Angle of local kyphosis } \\
\text { (at } 3 \text { years postoperative, }{ }^{\circ} \text { ) }\end{array}$ & $\begin{array}{l}\text { Loss of correction } \\
\text { of kyphosis over } 3 \\
\text { years }\left(^{\circ}\right)\end{array}$ & $\begin{array}{l}\text { Duration of } \\
\text { follow-up } \\
\text { (mo) }\end{array}$ \\
\hline
\end{tabular}

Group 1 (instrumented patients)

\begin{tabular}{|c|c|c|c|c|}
\hline 1 & 27 & 18 & 18 & 0 \\
\hline 2 & 25 & 7 & 7 & 0 \\
\hline 3 & 36 & 12 & 14 & 2 \\
\hline 4 & 38 & 13 & 14 & 1 \\
\hline 5 & 32 & 5 & 10 & 5 \\
\hline 6 & 37 & 8 & 10 & 2 \\
\hline 7 & 41 & 9 & 9 & 0 \\
\hline 8 & 25 & 8 & 9 & 1 \\
\hline 9 & 40 & 11 & 13 & 2 \\
\hline 10 & 36 & $\begin{array}{l}\text { Died on 2nd postoperative } \\
\text { day }^{\text {a) }}\end{array}$ & & \\
\hline 11 & 27 & 7 & 9 & 2 \\
\hline 12 & 37 & 6 & 7 & 1 \\
\hline 13 & 39 & 10 & 12 & 2 \\
\hline 14 & 36 & 8 & 9 & 1 \\
\hline 15 & 28 & 16 & 18 & 2 \\
\hline 16 & 39 & 5 & 6 & 1 \\
\hline 17 & 37 & 10 & 14 & 4 \\
\hline 18 & 28 & 7 & 10 & 3 \\
\hline
\end{tabular}

Group 2 (non instrumented patients)

\begin{tabular}{llllll}
1 & 34 & 29 & 34 & 5 & 36 \\
2 & 36 & 30 & 31 & 8 & 38 \\
3 & 22 & 18 & 31 & 13 & 42 \\
4 & 34 & 22 & 32 & 10 & 39 \\
5 & 35 & 26 & 33 & 7 & 37 \\
6 & 26 & 20 & 24 & 4 & 45 \\
7 & 45 & 38 & 46 & 8 & 39 \\
8 & 26 & 20 & 34 & 14 & 40 \\
9 & 28 & 27 & 31 & 4 & 42 \\
10 & 27 & 16 & 21 & 5 & 50 \\
11 & 35 & 28 & 30 & 2 & 37 \\
12 & 28 & 25 & 29 & 4 & 39 \\
13 & 35 & 30 & 38 & 8 & 40 \\
14 & 29 & 25 & 27 & 2 & 42 \\
\hline
\end{tabular}

${ }^{a}$ This was a 68-year-old female patient in the instrumented group (group 1). She had other associated comorbidities along with tuberculosis. The patient was a case of known coronary artery disease with poor cardiac and pulmonary reserve along with chronic hypertension. The patient died of acute myocardial infarction on the 2nd postoperative day. 
Table 3. Comparing the results of group 1 (instrumented patients) and group 2 (no implant was used)

\begin{tabular}{|c|c|c|}
\hline Criteria & Group $1(\mathrm{n}=18)$ & Group $2(n=14)$ \\
\hline Mean local kyphosis preoperative $\left(^{\circ}\right)$ & 33.6 & 31.4 \\
\hline Mean local kyphosis immediate postoperative $\left(^{\circ}\right)$ & 9.4 & 25.3 \\
\hline Late loss of correction ( 3 years postoperative, ${ }^{\circ}$ ) & 1.7 & 6.7 \\
\hline Canal compression preoperative $(\%)$ & 49.5 & 48.7 \\
\hline Canal compression postoperative $(\%)$ & 10 & 13.9 \\
\hline Improvement in canal compression $(\%)$ & 39.98 & 34.8 \\
\hline \multicolumn{3}{|l|}{ Frankel grade at the time of operation } \\
\hline Grade A & 16 & 13 \\
\hline Grade B & 1 & 2 \\
\hline Grade C, D, E & 0 & \\
\hline \multicolumn{3}{|l|}{ Frankel grade at 3 years follow-up } \\
\hline Grade A, B, C & 0 & 0 \\
\hline Grade D & 2 & 1 \\
\hline Grade E & 16 & 13 \\
\hline Number of days of stay at hospital following the operation (mean, day) & 11.4 & 11.8 \\
\hline Mortality & 1 & None \\
\hline Graft fracture, resorption, dislodgement & None & None \\
\hline
\end{tabular}

posterior hardware only given the fact that the infected zone is basically the anterior structures and involvement of posterior element is quite uncommon [13]. The true incidence of primary posterior involvement is unknown; however, the introduction of CT, MRI, and bone scans have increased the rate of identified cases to up to $10 \%$ of the cases $[14,15]$. Posterior fusion had been the standard surgical procedure for the limited correction and prevention of progression of deformity in many centers before the safe and liberal use of the anterior spinal surgery became feasible. However, posterior fusion does not appear to alter the natural course of the disease process. Pseudoarthrosis and bending of the fusion mass very frequently leads to substantial increase of the local kyphotic deformity [16-18]. Subsequently it has been shown that anterior instrumentation also is safe as far as the problem of persistent infection relating to the usage of foreign body is concerned [19-21].

Radical debridement with anterior approach and anterior fusion along with anterior strut grafts has come up in a big way in management of tubercular spondylitis in the present era [1]. As most of the spinal cord compression is usually located anteriorly, anterior approach and decompression is the preferred route for neural decompression [14-17]. Recently, posterolateral or transpedicular drainage without anterior drainage or posterior instrumentation following anterior drainage in the same session is offered as an alternative in attempts to avoid the kyphotic deformity [4,17,2224]. Posterior instrumentation in addition to anterior fusion, sequential or staged is associated with increased morbidity $[25,26]$. Use of anterior instrumentation has been reported on a limited number of series. Oga et al. [12] evaluated the adherence capacity of mycobacterium tuberculosis to stainless steel and demonstrated that adherence was negligible, and the use of implants in regions with active tuberculosis infection may be safe.

There are many studies in the literature that have demonstrated satisfactory results by anterior instrumentation providing several advantages $[1,19,20,27,28]$. Together with anterior fusion, additional anterior instrumentation has the following advantages: proper correction and stable alignment are maintained, graft-related complications are minimized. Spinal cord decompression is facilitated, good stability is provided. The patient does not need external support, so the rehabilitation is easier and quicker, complications related to the posterior procedure are eliminated, fusion is stimulated by rigid fixation [1]. Jain et al. [29,30] analysed all articles in which instrumented stabilisation was reported over the last 20 years. When anterior instrumentation $(\mathrm{n}=$ 
635) was used in tuberculous spondylitis, mean preoperative kyphosis was $25.35^{\circ}$, immediate postoperative kyphosis was $9.08^{\circ}$ and final kyphosis was $12.97^{\circ}$. There was an overall $2.3^{\circ}$ kyphosis progression after surgery [30].

In this study fibula was used for osteoconductive and structural support, whereas the rib, iliac crest were used for osteoinductivity [1]. The bone graft following uninstrumented anterior decompression in spinal tuberculosis provides sufficient stability and structural support in only $41 \%$ of patients with a short defect. The need for an external splint was suggested when the bone graft exceeds $5 \mathrm{~cm}$ (two-disc heights) to prevent graft-related complications [2,31]. However, the use of autologous bone is not without problems. Though we didn't encounter many problems due harvesting to autologous graft but haematomas, wound infections, neuropraxia, and pain are known complications when harvesting autologous bone [32]. In an effort to eliminate donor site morbidity, spinal surgeons have begun using fibular allograft, but to date, gold standard for cortical strut graft is still autologous fibula [32].

The strength of this study comes from that, a minimum period of 3 years follow-up has been done for all the patients. The immediate postoperative local kyphosis correction in the group 1 (instrumented) has been significantly $(p<0.05)$ more than that in group 2 however there has been no statistical difference between group 1 and 2 in terms of neurological improvement or the percentage of improvement in canal stenosis $(p>0.05)$. The late loss of correction of local kyphosis is significantly greater $(p<0.05)$ in the non instrumented group. We had one episode of mortality in group 1 in the immediate postoperative period and none in group 2 however that can be ascribed to associated comorbidities of that particular patient and had no relationship with the use of instrumentation.

Thus from our study in operative treatment of tubercular spondylitis, it is safe to say that anterior debridement, decompression of cord and autofibular strut grafting is an effective procedure and when performed in equipped centers, very few complications are noted and yields excellent results. Addition of anterior instrumentation improves the correction of local kyphosis and prevents late onset loss of correction and provides for early rehabilitation of the patient. The correction of local kyphosis in the instrumented group is more perhaps due to the rigid nature of screws and rods that do not allow loss of correction in kyphosis achieved after corpectomy and manual anterior pressure on the spine (see operative procedure in material and methods). This contrasts sharply with the non instrumented group in which the fibular strut graft which is not as rigid as metals and sometimes on account of graft subsidence during follow-up shows greater degree of loss of local kyphosis correction. There were no cases of graft dislodgement in the immediate postoperative radiographs (radiograph taken at postoperative day 3). Without the use of anterior instrumentation, only anterior debridement, decompression of cord and autofibular strut grafting is also associated with comparable neurological recovery at 3 years follow-up. However, the patients have to confine to bed for a longer period of time and local kyphosis would be more if anterior instrumentation were not used. Further, progression of kyphosis at 3 years followup is significantly more in the non instrumented group and though, local kyphosis is more in non instrumented group, both the groups have comparable neurological results at 3 years follow-up. The comparable neurological results in non instrumented group, despite of there being greater degree of kyphus can be ascribed to the fact that all our patients were of early onset paraparesis (duration from onset of symptoms to progression to paraparesis/plegia is less than 2 years) [33]. This comes on during active phase of the vertebral disease usually within the first 2 years of onset of the disease. Underlying pathology in most cases is inflammatory edema, tuberculous abscess, tuberculous caseous tissue [33]. Thus a thorough debridement of all infective tissues ensures adequate decompression of cord and hence the degree of local kyphosis does not correlate with the amount of neurological recovery in early onset paraparesis/plegia. Our cases do not include late onset paraparesis/plegia (duration from onset of symptoms to, progression to paraparesis/plegia is more than 2 years) [33], in whom the disease is not active the cause for compression is sequestra from vertebral body and disc, internal gibbus and severe deformity [33]. In these cases the degree of kyphosis correction may correlate with neurological recovery. Our late loss of kyphosis correction $\left(1.7^{\circ}\right.$ in instrumented patients and $6.7^{\circ}$ in non instrumented group) correlates well with other similar studies published in literature [27,28]. No case of apparent pseudoarthrosis or implant failures was observed. All patients demonstrated clinical healing of the tuberculosis infection and the surgical site wound. No recurrences, reactivation, drug resistance or draining sinuses were seen.

The belief that debridement of tubercular spondylitis lesion further destabilizes the spinal column and should always be combined with spinal instrumentation is challenged by this study with almost comparable neurological results in 
both instrumented and non instrumented groups. In the non instrumented group the favourable neurological results can be ascribed to prolonged period of immobilization until radiological signs of union were evident and to the prolonged use of spinal orthosis in this group. Morbidities due to prolonged immobilization, decreased correction of kyphosis in immediate postoperative period and further progression of kyphosis in due course of time are well known disadvantages of not using spinal instrumentation after debridement. There are instances though where instrumentation may not be advisable as in osteoporotic bones where the purchase of the screws may not be adequate and chances of implant failure shall be high. Active tubercular involvement of many contiguous vertebrae shall mean that many motion segments of the spine should be sacrificed as fixation should only be done in the adjacent healthy vertebrae. Thus a longer segment of spine will be immobilized as the instrumentation shall have to span a much longer distance. Use of instrumentation also needs expertise and increases the cost of the surgical treatment. We can hereby safely state that, though in tuberculous spondylitis after anterior debridement, anterior instrumentation and bone grafting is still the gold standard, in an occasional case where instrumentation is not feasible or is unsafe comparable neurological results can be achieved with thorough anterior debridement, spinal cord decompresion and strut grafting alone if adequate duration of immobilization, orthotic support and antitubercular drugs are given. It also reiterates the fact that anterior instrumentation is safe in tubercular spondylitis and is effective in correcting local kyphosis and in preventing further progression of kyphosis in the postoperative period. Instrumented stabilization also allows for earlier ambulation and better rehabilitation of the patients, reduces morbidity due to prolonged immobilization.

\section{Conclusions}

The use of anterior instrumentation is safe in tuberculous spondylitis. With the use of anterior instrumenatation the immediate postoperative local kyphosis correction, improvement in cosmetic deformity is better and the late loss of correction of local kyphosis is less compared with cases in which no instrumentation was done. In the treatment of tubercular spondylitis by anterior decompression of the spinal cord and autofibular strut grafting the use of instrumentation has no relation with the improvement in neurological status. What is most important is thorough removal of all infective tissues, good decompression of the spinal cord.

\section{REFERENCES}

1. Ozdemir HM, Us AK, Oğün T. The role of anterior spinal instrumentation and allograft fibula for the treatment of pott disease. Spine (Phila Pa 1976) 2003;28:474-9.

2. Rajasekaran S, Shanmugasundaram TK. Prediction of the angle of gibbus deformity in tuberculosis of the spine. J Bone Joint Surg Am 1987;69:503-9.

3. Guven O. Severe kyphotic deformity in tuberculosis of the spine. Int Orthop 1996;20:271.

4. Rezai AR, Lee M, Cooper PR, Errico TJ, Koslow M. Modern management of spinal tuberculosis. Neurosurgery 1995;36:87-97.

5. Benli IT, Alanay A, Akalin S, et al. Comparison of anterior instrumentation systems and the results of minimum 5 years follow-up in the treatment of tuberculosis spondylitis. Kobe J Med Sci 2004;50:167-80.

6. Chen CL, Chou CW, Su WW, Cheng CY, Yu CT. Dislodged upper thoracic cage in the gastrointestinal tract: a case report and literature reviews. Spine (Phila Pa 1976) 2008;33:E802-6.

7. Korovessis P, Petsinis G, Koureas G, Iliopoulos P, Zacharatos S. Anterior surgery with insertion of titanium mesh cage and posterior instrumented fusion performed sequentially on the same day under one anesthesia for septic spondylitis of thoracolumbar spine: is the use of titanium mesh cages safe? Spine (Phila Pa 1976) 2006;31:1014-9.

8. Oguz E, Sehirlioglu A, Altinmakas M, et al. A new classification and guide for surgical treatment of spinal tuberculosis. Int Orthop 2008;32:127-33.

9. Frankel HL, Hancock DO, Hyslop G, et al. The value of postural reduction in the initial management of closed injuries of the spine with paraplegia and tetraplegia. I. Paraplegia 1969;7:179-92.

10. Jain AK, Aggarwal A, Dhammi IK, Aggarwal PK, Singh S. Extrapleural anterolateral decompression in tuberculosis of the dorsal spine. J Bone Joint Surg Br 2004;86:1027-31.

11. Slucky AV, Eismont FJ. Spinal infections. In: Bridwell KH, Dewald RL, editors. The textbook of spinal surgery. Philadelphia: Lippincott; 1997. p. 2141-83.

12. Oga M, Arizono T, Takasita M, Sugioka Y. Evaluation of the risk of instrumentation as a foreign body in spinal tuberculosis. Clinical and biologic study. Spine (Phila 
Pa 1976) 1993;18:1890-4.

13. Babhulkar SS, Tayade WB, Babhulkar SK. Atypical spinal tuberculosis. J Bone Joint Surg Br 1984;66:23942.

14. Arthornthurasook A, Chongpieboonpatana A. Spinal tuberculosis with posterior element involvement. Spine (Phila Pa 1976) 1990;15:191-4.

15. Tuli SM. Severe kyphotic deformity in tuberculosis of the spine. Int Orthop 1995;19:327-31.

16. Aksoy MC, Acaroglu RE, Tokgozoglu AM, Ozdemir N, Surat A. Retrospective evaluation of treatment methods in tuberculosis spondylitis. Hacettepe J Orthop Surg 1995;5:207-9.

17. Hodgson AR, Stock FE. Anterior spinal fusion. A preliminary communication on the radical treatment of Pott's disease and Pott's paraplegia. 1956. Clin Orthop Relat Res 1994;(300):16-23.

18. Upadhyay SS, Saji MJ, Sell P, Yau AC. The effect of age on the change in deformity after radical resection and anterior arthrodesis for tuberculosis of the spine. $\mathrm{J}$ Bone Joint Surg Am 1994;76:701-8.

19. Yilmaz C, Selek HY, Gürkan I, Erdemli B, Korkusuz $Z$. Anterior instrumentation for the treatment of spinal tuberculosis. J Bone Joint Surg Am 1999;81:1261-7.

20. Benli IT, Acaroğlu E, Akalin S, Kiş M, Duman E, Un A. Anterior radical debridement and anterior instrumentation in tuberculosis spondylitis. Eur Spine J 2003;12:224-34.

21. Hassan MG. Anterior plating for lower cervical spine tuberculosis. Int Orthop 2003;27:73-7.

22. Hodgson AR, Stock FE, Fang HS, Ong GB. Anterior spinal fusion. The operative approach and pathological findings in 412 patients with Pott's disease of the spine. Br J Surg 1960;48:172-8.

23. Rajasekaran S, Soundarapandian S. Progression of kyphosis in tuberculosis of the spine treated by anterior arthrodesis. J Bone Joint Surg Am 1989;71:1314-23.

24. Loembe PM. Medical-surgical treatment of progressive tuberculous (Pott's) paraplegia in Gabon. Paraplegia 1995;33:579-84.

25. Schulitz KP, Kothe R, Leong JC, Wehling P. Growth changes of solidly fused kyphotic bloc after surgery for tuberculosis. Comparison of four procedures. Spine (Phila Pa 1976) 1997;22:1150-5.

26. A 15-year assessment of controlled trials of the management of tuberculosis of the spine in Korea and Hong Kong. Thirteenth report of the medical research council working party on tuberculosis of the spine. J Bone Joint Surg Br 1998;80:456-62.

27. Benli IT, Aydın E, Kis M, Akalın S, Tuzuner M, Baz $\mathrm{AB}$. The results of anterior instrumentation in vertebral tuberculosis. J Turkish Spine Surg 1996;7:98-101.

28. Benli IT, Kiş M, Akalin S, Citak M, Kanevetçi S, Duman $\mathrm{E}$. The results of anterior radical debridement and anterior instrumentation in Pott's disease and comparison with other surgical techniques. Kobe J Med Sci 2000;46:39-68.

29. Jain AK. Tuberculosis of the spine: a fresh look at an old disease. J Bone Joint Surg Br 2010;92:905-13.

30. Jain AK, Dhammi IK, Jain S, Mishra P. Kyphosis in spinal tuberculosis: prevention and correction. Indian J Orthop 2010;44:127-36.

31. Rajasekaran S. The problem of deformity in spinal tuberculosis. Clin Orthop Relat Res 2002;(398):85-92.

32. Gore DR, Sepic SB. Anterior cervical fusion for degenerated or protruded discs. A review of one hundred forty-six patients. Spine (Phila Pa 1976) 1984;9:66771.

33. Tuli SM. Tuberculosis of the skeletal system: bones, joints, spine and bursal sheaths. New Delhi: Jaypee Brothers Medical; 1991. 